九州大学学術情報リポジトリ

Kyushu University Institutional Repository

大腸びまん性大細胞型 $B$ 細胞性リンパ腫における分 子学的亜分類ならびに免疫グロブリン遺伝子転座の 予後因子としての意義について

保利，喜史

http://hdl. hand le. net/2324/4060045

出版情報: Kyushu University，2019，博士（医学），課程博士 バージョン：

権利関係：○ 2019 Elsevier Inc. All rights reserved. 


\title{
Colorectal diffuse large B-cell lymphoma: molec- ular subclassification and prognostic significance of immunoglobulin gene translocation
}

\author{
Yoshifumi Hori MD ${ }^{a}$, Hidetaka Yamamoto MD, PhD ${ }^{a}$, Yui Nozaki MD ${ }^{a}$, \\ Takehiro Torisu MD, $\mathrm{PhD}^{\mathrm{b}}$, Minako Fujiwara MD, $\mathrm{PhD}^{\mathrm{a}}$, Kenichi Taguchi MD, $\mathrm{PhD}^{\mathrm{c}}$, \\ Kenichi Nishiyama MD, PhD ${ }^{d}$, Shotaro Nakamura MD, PhD ${ }^{e}$, \\ Takanari Kitazono MD, PhD ${ }^{b}$, Yoshinao Oda MD, PhD ${ }^{a, *}$
}

\author{
${ }^{a}$ Department of Anatomic Pathology, Kyushu University, Japan \\ ${ }^{\mathrm{b}}$ Department of Medicine and Clinical Science, Graduate School of Medical Sciences, Kyushu University, Japan \\ ${ }^{\mathrm{c}}$ Department of Pathology, National Kyushu Cancer Center, Fukuoka, Japan \\ ${ }^{\mathrm{d}}$ Department of Pathology, Fukuoka Red Cross Hospital, Fukuoka, Japan \\ ${ }^{\mathrm{e}}$ Division of Gastroenterology, Department of Internal Medicine, School of Medicine, Iwate Medical University, Morioka, \\ Japan
}

Received 21 May 2019; revised 6 September 2019; accepted 9 September 2019

\author{
Diffuse large B-cell lym- \\ phoma; \\ Colon; \\ Rectum; \\ Translocation; \\ Immunoglobulin; \\ Prognosis

\section{Keywords:} \\ Prognosis
}

\begin{abstract}
Summary Primary colorectal diffuse large B-cell lymphoma (DLBCL) is rare, and its clinicopathological and genetic features are poorly understood. The aim of our study was to elucidate the frequency and prognostic significance of molecular subgroups in colorectal DLBCL. We examined 25 cases of colorectal lymphoma with DLBCL-like morphology and classified them into germinal center B-cell like (GCB)/non-GCB subgroups by immunohistochemistry (IHC) for CD10, bcl-6 and MUM1, or into double-expressor (DE)/non-DE subgroups by IHC for bcl-2 and c-myc. Translocations involving BCL2, $B C L 6, M Y C, I G H, I G K, I G L$, and MALT1 were also investigated using break-apart fluorescence in situ hybridization (FISH). The 25 cases were classified into two entities-DLBCL, not otherwise specified (NOS) $(n=23 ; 92 \%)$ and high grade B-cell lymphoma, double hit $(\mathrm{n}=2 ; 8 \%)$-according to the recent WHO classification. None of them showed histological evidence of Epstein-Barr virus infection or high-grade transformation from low grade B-cell lymphoma. Ten cases were GCB-type and four cases were DE-type, but these subtypes did not contribute to clinicopathological differences. Translocations involving BCL2, BCL6, MYC, IGH, IGK, IGL, and MALT1 were detected in $3(12 \%), 3(12 \%), 10$ (40\%), $14(56 \%), 3(12 \%), 3(12 \%)$, and $0(0 \%)$ of 25 cases, respectively. Of note, the presence of $I G H$ translocation was significantly associated with better overall survival $(P=.0053)$ and progression free survival $(P=.0259)$. Similarly, the translocation involving at least one of the $I G$ s $(I G H, I G K$, and/
\end{abstract}

it Conflicts of interest/Disclosures: The authors declare that there are no conflicts of interest to disclose.

is ts Acknowledgements: We are grateful to Hiroaki Miyoshi, Koichi Ohshima, Shinichi Kawano, Koji Ikegami, Yuichi Matsuno, Keizou Zeze, Takahide Tanaka, Takashi Hirata, Motohiro Esaki, and Shinichi Tsuruta for scientific support, and Naoko Ieiri and Mami Nakamizo for technical assistance. The English in this article was edited by KN international (http://www.kninter.com/).

* Corresponding author at: Department of Anatomic Pathology, Pathological Sciences, Graduate School of Medical Sciences, Kyushu University, Maidashi 3-1-1, Higashi-ku, Fukuoka 812-8582, Japan.

E-mail address: oda@surgpath.med.kyushu-u.ac.jp (Y. Oda). 
or $I G L)$ was associated with more favorable prognosis in DLBCLs or even in DLBCL, NOS. This is the first report to reveal that a small subset of colorectal DLBCL corresponds to double-hit lymphoma. In addition, translocations involving at least one of the $I G$ s may be a favorable prognostic factor in colorectal DLBCL. Testing the translocation involving rearrangement of $I G \mathrm{~s}$ as well as MYC and BCL2/ $B C L 6$ may thus be useful for diagnosis and prognosis.

(C) 2019 Elsevier Inc. All rights reserved.

\section{Introduction}

Primary colorectal lymphoma is very rare, accounting for $0.2 \%$ to $0.6 \%$ of all colonic malignancies and $10 \%$ to $20 \%$ of gastrointestinal (GI) non-Hodgkin lymphoma [1,2]. Nevertheless, diffuse large B-cell lymphoma (DLBCL) is relatively common among colorectal lymphomas [1-7]. DLBCL is often difficult to treat and the continuing subject of interest among pathologists, hematologists and gastroenterologists. According to the recent World Health Organization (WHO) classification published in 2017, colorectal B-cell lymphoma and lymphoproliferative disorder (LPD) with DLBCL-like morphology can be subdivided into the following categories: (i) DLBCL, not otherwise specified (NOS), (ii) high-grade Bcell lymphoma with $M Y C$ and $B C L 2$ and/or BCL6 rearrangements [so-called double-hit lymphoma (DHL): HGBL-DH], (iii) Epstein-Barr virus (EBV)-positive DLBCL, NOS (formerly, age-related LPD), (iv) EBV-positive mucocutaneous ulcer, and (v) immunodeficiency-associated LPD (including primary immune disorder, human immunodeficiency virus infection, post-transplant and other iatrogenic conditions) [3]. These lymphomas should be distinguished from Burkitt lymphoma (BL) or morphologically BL-like lymphomas such as HGBL-DH and HGBL-NOS.

DLBCL is a clinically, immunologically and genetically heterogenous group of lymphomas [3,8-10]. As for nodal DLBCLs, HGBL-DH (DHL) is considered to have an aggressive biological behavior $[11,12]$. The double expressor, as defined by the co-expression of c-myc and bcl-2, are also an aggressive subgroup of DLBCL [13-15]. According to the gene expression profile, the germinal center B-cell like (GCB) subtype is thought to have a more favorable prognosis than the non-GCB or activated B-cell-like (ABC) subtype among DLBCLs [16]. However, the prevalence and clinicopathological significance of these subtypings have been unclear in primary DLBCL of the GI tract, especially of the large intestine [17].

The reported cytogenic abnormalities in DLBCL include the translocations involving IGH (14q32), IGK (2p12), IGL (22q11), BCL2 (18q21), BCL6 (3q27), MYC (8q24), API2 (11q21) and MALT1 (18q21) [18,19]. Nevertheless, it is not easy to examine all the above translocations at the daily practice level, while the G-band of chromosomal inspection is not sufficiently sensitive, and next-generation sequencing is expensive [8-10]. Therefore, it is necessary to establish biomarkers that are cost-effective and useful for diagnosis and prognosis. We previously reported that translocations involving $I G H$ are associated with favorable prognosis in patients with gastric and small bowel DLBCLs [20,21]. In this study, we attempted to classify colorectal DLBCLs according to the recent WHO classification, and to elucidate the clinicopathological significance of molecular subtyping and candidate gene rearrangements.

\section{Materials and methods}

\subsection{Subjects}

Data on cases of colorectal lymphomas with DLBCL-like morphology $(\mathrm{n}=25)$ were retrieved from the files of Kyushu University Hospital and its affiliated hospitals between 1999 and 2018. All cases satisfied the criteria for primary gastrointestinal lymphoma as defined by Lewin et al [22]. A method for discriminating primary colorectal lymphomas from systemic lymphomas involving the large intestine has not been fully developed, but in the current study we considered a case to be colorectal primary if the main bulk of the lesions were located in the large intestine in the current study [2,4-6]. All cases were histologically reviewed by two pathologists (mostly Y.H. and H.Y.), and the morphological diagnosis of DLBCL was confirmed according to the criteria of WHO classification [3]. Immunodeficiency-associated LPDs with DLBCL morphology were excluded in the current study. Although pleomorphic mantle cell lymphoma can show DLBCL-like morphology, we confirmed that both CD5 and cyclin D1 were immunohistochemically negative in all 25 cases. Burkitt lymphoma (BL) and high-grade lymphoma with BL-like morphology were also excluded. The clinical stage was determined according to the Lugano classification [23]. Staging workup included computed tomography of the neck, chest, and abdomen, esophagogastroduodenoscopy, colonoscopy, small bowel endoscopy (double-balloon and/or capsule endoscopy) or barium radiography, bone marrow aspiration/biopsy, and fluorine-18 fluorodeoxyglucose positron emission tomography. The international prognostic index (IPI) for aggressive lymphoma was classified as low, low-intermediate, intermediate-high or high risk [24]. The macroscopic growth pattern was classified as polypoid, ulcerative, lymphomatous polyposis, diffuse-infiltrating, or mixed by three experienced endoscopists (S.N., T.T., and Y.H.) based on the endoscopic findings in 8 cases and on 
the surgical excision specimens in 17 cases $[6,20,21]$. The initial treatment modalities included surgical resection, chemotherapy with a cyclophosphamide, doxorubicin, vincristine and prednisolone (CHOP)-based regimen with or without rituximab, radiotherapy, or a combination of them. Complete remission (CR) was defined as the complete disappearance of clinical evidence of lymphoma. Partial remission (PR) was defined as a tumor reduction of $\geq 50 \%$. The resected or biopsied specimens were fixed in $10 \%$ formalin solution, embedded in paraffin and cut into $4-\mu m$-thick slices for subsequent analysis. This retrospective study was approved by the Institutional Review Board of Kyushu University (no.29-240) and the National Kyushu Cancer Center (no.2017-56).

\subsection{Immunohistochemical staining}

For immunohistochemistry (IHC), we used the primary mouse monoclonal antibodies against CD10 (clone 56C6, 1:100 dilution; Leica Biosystems, Newcastle upon Tyne, UK), bcl-2 (clone 124, 1:100 dilution; Dako), bcl-6 (clone PG-B6p, 1:10 dilution; Dako), MUM1 (clone MUM1p, 1:50 dilution; Dako) and c-myc (clone Y69, 1:100 dilution; Abcam, Cambridge, UK). Samples in which more than $30 \%$ of tumor cells were immunoreactive were considered to be positive for CD10, bcl-6 and MUM1 [3,20,21]. Thereafter, tumors were classified as either GCB or non-GCB phenotype according to the algorithm of Hans [25]. Moreover, the cut-off points for c-myc and bcl-2 were defined as $40 \%$ or more and $50 \%$ or more, respectively $[3,14,15,26]$.

\subsection{Fluorescence in situ hybridization (FISH)}

Gene translocation was investigated by interphase fluorescence in situ hybridization (FISH) on FFPE with dual-color, break-apart rearrangement probes for $B C L 2, B C L 6, M Y C$, $I G H, M A L T 1$ (Vysis-Abbott, Des Plaines, IL), IGK and IGL (Cytocell Technologies, Cambridge, UK) as previously described [20,21]. Cases with both $I G H$ and $B C L 2$ rearrangements by break-apart FISH were further investigated by FISH with $I G H / B C L 2$ dual-color, dual fusion translocation probe (Vysis-Abbott, Des Plaines, IL). Likewise, cases with both $I G H$ and $M Y C$ rearrangements were examined by FISH with IGH/MYC/CEP8 tri-color, dual fusion probe (Vysis). FISH analysis was performed using direct viewing on a standard fluorescence microscope (BX53; Olympus, Tokyo). Cut-off levels were the same as those in previous studies $[20,21]$. If three or more gene copies were detected in tumor cells, the result was categorized as a copy number gain, as described in the previous studies $[20,21]$.

\subsection{In situ hybridization for EBV infection}

To test for the presence of EBV, in situ hybridization (ISH) was performed on FFPE with an EBV-encoded
RNA (EBER)-specific peptide nucleic acid (PNA) probe and a PNA ISH detection kit (Dako Cytomation, Carpinteria, CA) according to the manufacturer's instruction, as previously described [27]. EBV-positive gastric cancer with lymphoid stroma was used as the positive control.

\subsection{Statistical analysis}

Overall survival (OS) was defined as the time from the date of diagnosis to the date of death from a tumor-specific cause. Progression-free survival (PFS) was defined as the time from the date of diagnosis to the date when progressive disease (PD) was first documented or relapse was confirmed clinically. The OS and PFS rates were calculated with the Kaplan-Meier method, and values were compared by using the log-rank test. Other differences were evaluated with Fisher's exact test, the $\chi^{2}$ test, or the Mann-Whitney $U$ test. $P$ values of $<.05$ were considered to be statistically significant. All analyses were performed with JMP PRO 13 software (SAS Institute, Cary, NC).

\section{Results}

\subsection{Clinical features}

Clinicopathological findings are shown in Table 1 and summarized in Supplemental Table S1. The patients were diagnosed at the mean age of 66 years (range: $38-84$ years) with a slight male predominance (male: female $=1.27: 1$ ). The most frequent tumor location was the cecum $(n=17,68 \%)$. Sixteen patients (64\%) had a single tumor located in the large intestine, whereas nine (36\%) had multiple tumors, with the main lesion being located in the large intestine. Among cases with multiple tumors, the smaller tumors were present in the ileum $(\mathrm{n}=8,32 \%)$ or stomach $(\mathrm{n}=1,4 \%)$. The macroscopic type was classified as the ulcerative type in 11 patients (44\%), the polypoid type in $12(48 \%)$, mixed-type in 1 $(4 \%)$, and diffuse type in $1(4 \%)$. No patients had lymphomatous polyposis-type tumors. The clinical stage was I in 9 patients (36\%), II1 in 2 patients (8\%), II2 in 3 patients (12\%), IIE in 4 patients (16\%), and IV in 7 patients (28\%). The IPI risk was low in 11 patients (44\%), low-intermediate in 7 patients (28\%), high-intermediate in 5 patients $(20 \%)$, and high in 2 patients (8\%). Seventeen patients (68\%) underwent surgical resection followed by chemotherapy with a cyclophosphamide, doxorubicin, vincristine and prednisolone (CHOP)-based regimen with or without rituximab, 5 patients (20\%) received chemotherapy without surgical resection and 2 patients $(8 \%)$ received radiation therapy after chemotherapy, and 1 patient (4\%) underwent surgery alone. As a result, 17 patients (71\%) achieved CR, $4(16 \%)$ achieved PR, and 3 (13\%) showed PD. The follow-up duration after diagnosis ranged from 3 to 187 months (median: 54 months). During 
Table 1 Clinicopathological findings in 25 cases of colorectal large B-cell lymphoma

\begin{tabular}{|c|c|c|c|c|c|c|c|c|c|c|c|c|c|}
\hline Case & Age & Sex & $\begin{array}{l}\text { Size } \\
(\mathrm{mm})\end{array}$ & Site & Multiplicity & $\begin{array}{l}\text { Macroscopic } \\
\text { type }\end{array}$ & $\begin{array}{l}\text { Clinical } \\
\text { stage } \\
\text { (Lugano) }\end{array}$ & IPI & Colectomy & Initial treatment & $\begin{array}{l}\text { Response } \\
\text { to initial } \\
\text { treatment }\end{array}$ & $\begin{array}{l}\text { Progression/relapse, } \\
\text { follow-up period } \\
\text { (months) }\end{array}$ & $\begin{array}{l}\text { Tumor specific death, } \\
\text { follow-up period } \\
\text { (months) }\end{array}$ \\
\hline \multicolumn{14}{|c|}{ DLBCL, NOS $(\mathrm{n}=23)$} \\
\hline 1 & 38 & $\mathrm{~F}$ & 27 & Cecum & Single & Ulcerative & II2 & 0 & $(-)$ & R-CHOP & $\mathrm{CR}$ & $(-, 83 \mathrm{mo})$ & $(-, 83 \mathrm{mo})$ \\
\hline 2 & 56 & $\mathrm{~F}$ & 135 & Cecum & Multiple & Polypoid & IV & 3 & $(+)$ & R-CHOP & $\mathrm{CR}$ & $(+, 75 \mathrm{mo})$ & $(+, 92 \mathrm{mo})$ \\
\hline 3 & 64 & M & 47 & Cecum & Multiple & Polypoid & IV & 2 & $(-)$ & R-CHOP & $\mathrm{CR}$ & $(-, 53 \mathrm{mo})$ & $(-, 53 \mathrm{mo})$ \\
\hline 4 & 64 & M & 40 & Colon & Single & Ulcerative & IIE & 2 & $(+)$ & R-CHOP & $\mathrm{CR}$ & $(-, 79 \mathrm{mo})$ & $(-, 79 \mathrm{mo})$ \\
\hline 5 & 51 & M & 87 & Cecum & Single & Ulcerative & IIE & 1 & $(+)$ & R-CHOP & $\mathrm{CR}$ & $(-, 118 \mathrm{mo})$ & $(-, 118 \mathrm{mo})$ \\
\hline 6 & 74 & $\mathrm{~F}$ & 68 & Cecum & Multiple & Ulcerative & IV & 3 & $(+)$ & R-CHOP & PR & $(-, 8 \mathrm{mo})$ & $(-, 8 \mathrm{mo})$ \\
\hline 7 & 71 & M & 31 & Cecum & Single & Polypoid & I & 1 & $(+)$ & $(-)$ & $(-)$ & $(-, 28 \mathrm{mo})$ & $(-, 28 \mathrm{mo})$ \\
\hline 8 & 69 & $\mathrm{~F}$ & 55 & Cecum & Single & Ulcerative & II1 & 1 & $(+)$ & R-CHOP & PR & $(-, 20 \mathrm{mo})$ & $(-, 20 \mathrm{mo})$ \\
\hline 9 & 67 & $\mathrm{M}$ & 85 & Colon & Multiple & Polypoid & II2 & 4 & $(+)$ & ESHAP & PD & $(+, 1 \mathrm{mo})$ & $(+, 3 \mathrm{mo})$ \\
\hline 10 & 74 & M & 90 & Cecum & Multiple & Ulcerative & IV & 3 & $(+)$ & EPOCH & PD & $(+, 3 \mathrm{mo})$ & $(+, 8 \mathrm{mo})$ \\
\hline 11 & 84 & $\mathrm{M}$ & 80 & Colon & Multiple & Mixed & IV & 2 & $(-)$ & R-CHOP & $\mathrm{CR}$ & $(+, 44 \mathrm{mo})$ & $(+, 44 \mathrm{mo})$ \\
\hline 12 & 66 & $\mathrm{~F}$ & 60 & Cecum & Multiple & Polypoid & II1 & 2 & $(+)$ & THP-COP & PD & $(+, 4 \mathrm{mo})$ & $(+, 9 \mathrm{mo})$ \\
\hline 13 & 59 & $\mathrm{M}$ & 100 & Rectum & Single & Polypoid & I & 2 & $(-)$ & THP-COP & $\mathrm{CR}$ & $(+, 12 \mathrm{mo})$ & $(+, 56 \mathrm{mo})$ \\
\hline 14 & 64 & M & 50 & Cecum & Single & Polypoid & II 2 & 1 & $(+)$ & $\begin{array}{l}\text { THP-COP + } \\
\text { Radiation }\end{array}$ & $\mathrm{CR}$ & $(+, 13 \mathrm{mo})$ & $(-, 39 \mathrm{mo})$ \\
\hline 15 & 78 & $\mathrm{M}$ & 49 & Cecum & Multiple & Polypoid & I & 1 & $(+)$ & R-CHOP & $\mathrm{CR}$ & $(-, 45 \mathrm{mo})$ & $(-, 45 \mathrm{mo})$ \\
\hline 16 & 53 & $\mathrm{~F}$ & 48 & Cecum & Single & Polypoid & I & 0 & $(+)$ & R-CHOP & $\mathrm{CR}$ & $(-, 187 \mathrm{mo})$ & $(-, 187 \mathrm{mo})$ \\
\hline 17 & 73 & $\mathrm{~F}$ & 110 & Cecum & Single & Ulcerative & IIE & 3 & $(+)$ & $\mathrm{CHOP}$ & $\mathrm{CR}$ & $(-, 95 \mathrm{mo})$ & $(-, 95 \mathrm{mo})$ \\
\hline 18 & 63 & $\mathrm{~F}$ & 42 & Cecum & Multiple & Polypoid & I & 1 & $(+)$ & $\mathrm{CHOP}$ & $\mathrm{CR}$ & $(-, 58 \mathrm{mo})$ & $(-, 58 \mathrm{mo})$ \\
\hline 19 & 79 & M & 103 & Rectum & Single & Polypoid & IV & 4 & $(-)$ & R-CHOP & PR & $(-, 2 \mathrm{mo})$ & $(-, 2 \mathrm{mo})$ \\
\hline 20 & 65 & $\mathrm{~F}$ & 94 & Cecum & Single & Ulcerative & I & 1 & $(+)$ & R-THP-COP & $\mathrm{CR}$ & $(-, 82 \mathrm{mo})$ & $(-, 82 \mathrm{mo})$ \\
\hline 21 & 71 & M & 60 & Cecum & Single & Polypoid & I & 3 & $(+)$ & R-CHOP & $\mathrm{CR}$ & $(-, 101 \mathrm{mo})$ & $(-, 101 \mathrm{mo})$ \\
\hline 22 & 61 & M & 104 & Rectum & Single & Ulcerative & I & 1 & $(+)$ & R-CHOP & $\mathrm{CR}$ & $(-, 14 \mathrm{mo})$ & $(-, 14 \mathrm{mo})$ \\
\hline 23 & 60 & $\mathrm{~F}$ & 100 & Rectum & Single & Ulcerative & I & 0 & $(-)$ & $\begin{array}{l}\mathrm{R}-\mathrm{CHOP}+ \\
\text { Radiation }\end{array}$ & $\mathrm{CR}$ & $(-, 8 \mathrm{mo})$ & $(-, 8 \mathrm{mo})$ \\
\hline \multicolumn{14}{|c|}{ HGBL-DH $(n=2)$} \\
\hline 24 & 68 & M & 140 & Cecum & Single & Ulcerative & IIE & 2 & $(+)$ & R-ESHAP & PR & $(+, 61 \mathrm{mo})$ & $(-, 85 \mathrm{mo})$ \\
\hline 25 & 77 & $\mathrm{~F}$ & 93 & Colon & Single & Diffuse & IV & 2 & $(-)$ & R-THP-COP & $\mathrm{CR}$ & $(+, 4 \mathrm{mo})$ & $(+, 6 \mathrm{mo})$ \\
\hline
\end{tabular}


the follow-up period, 3 patients (13\%) who had initially been treated with surgery plus chemotherapy showed PD. A total of 9 patients (36\%) died and 7 (28\%) of them died of lymphoma. Of the 2 remaining patients, 1 patient (4\%) died of esophageal cancer, and the other patient (4\%) died from pneumoniae post chemotherapy. The OS and PFS rates after 5 years were $75 \%$ and $68 \%$, respectively (Supplemental Fig. S1).

\subsection{Histopathological findings}

Histopathologically, all cases showed diffuse proliferation of CD20-positive centroblast-like or immunoblast-like large atypical lymphoid cells (Fig. 1A and B). None of them revealed morphologically definite findings of high grade transformation from low grade B-cell lymphoma, such as follicular lymphoma and MALToma. EBV-EBER was negative in all cases, which excluded both EBV-positive DLBCL, NOS and EBV-positive mucocutaneous ulcer. According to the immunohistochemical and molecular findings, our cases were classifiable into two categories; DLBCL, NOS ( $\mathrm{n}=$ 23, 92\%) (cases 1-23) and HGBL-DH $(\mathrm{n}=2,8 \%)$ (case 24 and 25) (see below) (Table 1).

\subsection{Immunohistochemical findings}

Immunohistochemically, CD10, bcl-2, bcl-6, MUM1, and c-myc were positive in 8/25 (32\%), 14/25 (56\%), 15/25 (60\%), 17/25 (68\%), and 7/25 (28\%) cases, respectively (Table 2 and Supplemental Table S2). According to the algorithm of Hans [25], $10(40 \%)$ and $15(60 \%)$ cases were subdivided into the GCB and non-GCB phenotype, respectively. Among 23 cases of DLBCL, NOS, 9 (39\%) were GCB type and $14(61 \%)$ were non-GCB type (Table 2, Supplemental Fig. S2). Among cases of HGBL-DH ( $\mathrm{n}=$ 2), 1 belonged to the GCB and 1 to the non-GCB phenotype. Four of $25(16 \%)$ cases were consistent with double expressor (DE). These cases comprised of $3 / 23(13 \%)$ cases of DLBCL, NOS and 1/2 (50\%) cases of HGBL-DH. In other words, $1 / 4(25 \%)$ cases of DE lymphoma and 1/21 (5\%) cases of non-DE lymphoma was a case of HGBL-DH.

\subsection{Gene translocations by FISH}

Break-apart FISH was successful in all 25 cases. A retrospective split signal on FISH is shown in Fig. 1C. Gene rearrangements suspicious for translocations involving $I G H, I G K, I G L$, $B C L 2, B C L 6$, and MYC were detected in 14 (56\%), $3(12 \%), 3$ (12\%), $3(12 \%), 3(12 \%)$, and 10 (40\%) of 25 cases, respectively (Fig. 2, Supplemental Table S2). No cases harboring MALT1 translocation were observed. Among the 10 patients with $M Y C$ rearrangements, breakage of $B C L 2$ was observed in 1 case (case 24) and breakage of BCL6 in 1 case (case 25); that is, 2 cases corresponded to HGBL-DH (Fig. 2). One of the 2 HGBL-DHs also had IGH-MYC translocation confirmed by dual-fusion FISH
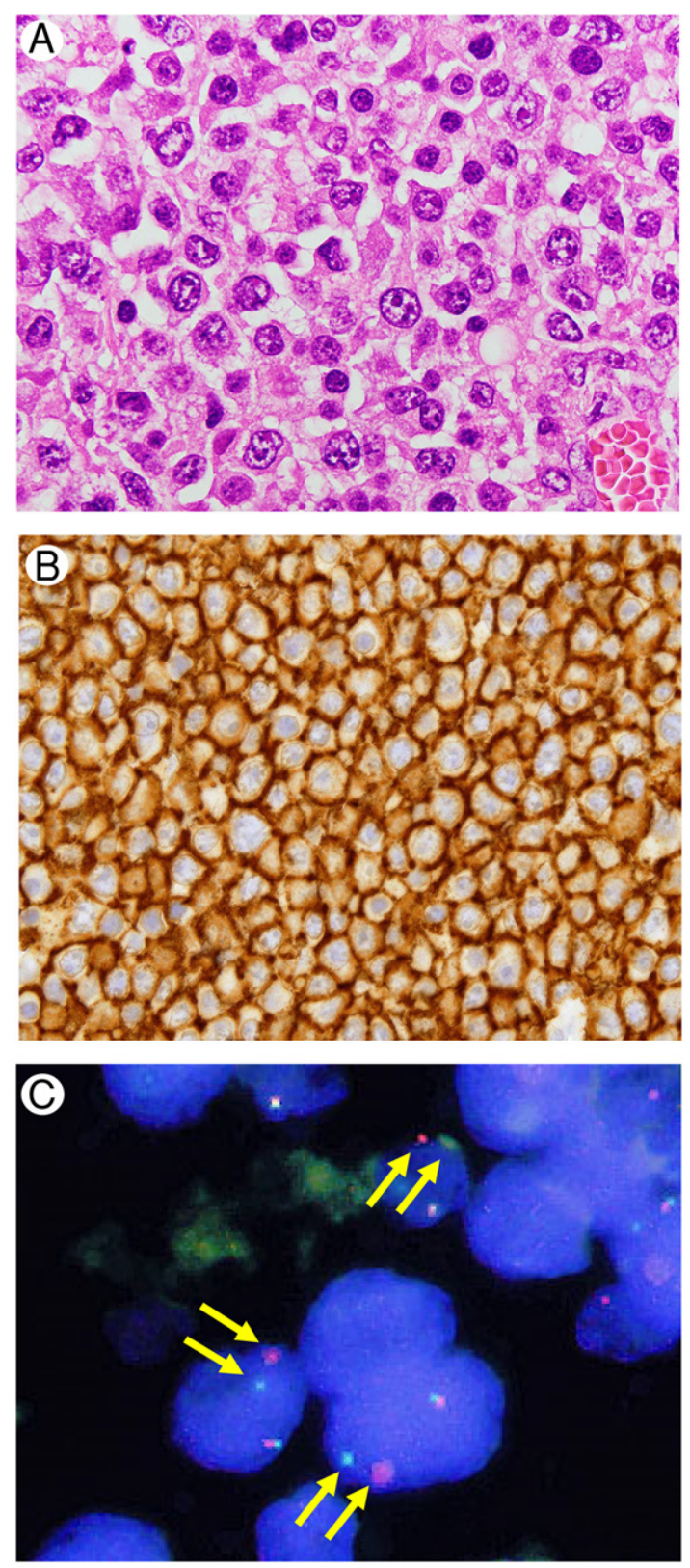

Fig. 1 A representative case of colorectal diffuse large B-cell lymphoma. A, A high-power histological view shows diffuse infiltrates of large, atypical lymphoid cells (hematoxylin and eosin stain). B, Immunohistochemically, the neoplastic cells are positive for CD20. C, Interphase fluorescence in situ hybridization with an $I G H$ dual-color break-apart probe shows a split of green and red signals (indicated by arrows), indicating the presence of a translocation.

(cases 25) (Supplemental Table S3). Among the 14 patients with $I G H$ rearrangements, breakage of $B C L 2, B C L 6$ and MYC was detected in 2 (14\%), 3 (21\%), and 5 (36\%) cases, respectively (Fig. 2). Among the 5 cases (cases 1, 5, 10, 19 and 25) with both $I G H$ and $M Y C$ rearrangements by break-apart FISH, IGH-MYC translocation was confirmed in 2 cases (cases 5 and 25) by dual-fusion FISH (Supplemental Table S3). Of the 2 cases (cases 3 and 20) with both $I G H$ and $B C L 2$ rearrangements by break- 
Table 2 Immunohistochemical results in 25 cases of colorectal large B-cell lymphoma

\begin{tabular}{|c|c|c|c|c|c|c|c|c|}
\hline Case & CD10 & bcl-2 & bcl-6 & MUM1 & c-myc & Double expressor & MIB-1 (\%) & Hans \\
\hline \multicolumn{9}{|c|}{ DLBCL, NOS $(n=23)$} \\
\hline 1 & $(+)$ & $(+)$ & $(+)$ & $(+)$ & $(+)$ & $(+)$ & $>95$ & GCB \\
\hline 2 & $(+)$ & $(+)$ & $(+)$ & $(+)$ & $(+)$ & $(+)$ & $90-95$ & GCB \\
\hline 3 & $(+)$ & $(+)$ & $(+)$ & $(+)$ & $(-)$ & $(-)$ & 60 & GCB \\
\hline 4 & $(-)$ & $(-)$ & $(+)$ & $(-)$ & $(-)$ & $(-)$ & 64 & GCB \\
\hline 5 & $(+)$ & $(-)$ & $(+)$ & $(-)$ & $(-)$ & $(-)$ & $90-95$ & GCB \\
\hline 6 & $(+)$ & $(+)$ & $(+)$ & $(+)$ & $(-)$ & $(-)$ & 90 & GCB \\
\hline 7 & $(+)$ & $(+)$ & $(+)$ & $(+)$ & $(-)$ & $(-)$ & 90 & GCB \\
\hline 8 & $(+)$ & $(-)$ & $(-)$ & $(-)$ & $(+)$ & $(-)$ & 85 & GCB \\
\hline 9 & $(-)$ & $(+)$ & $(+)$ & $(-)$ & $(-)$ & $(-)$ & 67 & GCB \\
\hline 10 & $(-)$ & $(+)$ & $(-)$ & $(+)$ & $(+)$ & $(+)$ & 90 & Non-GCB \\
\hline 11 & $(-)$ & $(-)$ & $(-)$ & $(-)$ & $(-)$ & $(-)$ & 85 & Non-GCB \\
\hline 12 & $(-)$ & $(-)$ & $(-)$ & $(-)$ & $(-)$ & $(-)$ & 66 & Non-GCB \\
\hline 13 & $(-)$ & $(+)$ & $(-)$ & $(+)$ & $(-)$ & $(-)$ & 90 & Non-GCB \\
\hline 14 & $(-)$ & $(+)$ & $(+)$ & $(+)$ & $(-)$ & $(-)$ & 50 & Non-GCB \\
\hline 15 & $(-)$ & $(-)$ & $(-)$ & $(+)$ & $(-)$ & $(-)$ & 60 & Non-GCB \\
\hline 16 & $(-)$ & $(+)$ & $(+)$ & $(+)$ & $(-)$ & $(-)$ & 59 & Non-GCB \\
\hline 17 & $(-)$ & $(-)$ & $(+)$ & $(+)$ & $(-)$ & $(-)$ & 80 & Non-GCB \\
\hline 18 & $(-)$ & $(+)$ & $(-)$ & $(-)$ & $(-)$ & $(-)$ & 80 & Non-GCB \\
\hline 19 & $(-)$ & $(-)$ & $(+)$ & $(+)$ & $(+)$ & $(-)$ & 75 & Non-GCB \\
\hline 20 & $(-)$ & $(-)$ & $(-)$ & $(-)$ & $(-)$ & $(-)$ & 50 & Non-GCB \\
\hline 21 & $(-)$ & $(+)$ & $(-)$ & $(+)$ & $(-)$ & $(-)$ & $>95$ & Non-GCB \\
\hline 22 & $(-)$ & $(-)$ & $(-)$ & $(+)$ & $(+)$ & $(-)$ & 90 & Non-GCB \\
\hline 23 & $(-)$ & $(+)$ & $(+)$ & $(+)$ & $(-)$ & $(-)$ & 89 & Non-GCB \\
\hline \multicolumn{9}{|c|}{ HGBL-DH $(\mathrm{n}=2)$} \\
\hline 24 & $(+)$ & $(-)$ & $(+)$ & $(+)$ & $(-)$ & $(-)$ & $>95$ & GCB \\
\hline 25 & $(-)$ & $(+)$ & $(+)$ & $(+)$ & $(+)$ & $(+)$ & 90 & Non-GCB \\
\hline
\end{tabular}

Abbreviation: GCB, germinal center B-cell-like. Immunophenotype by Hans classification.

apart FISH, IGH-BCL2 translocation was confirmed in one case (case 20) by dual-fusion FISH. Of all 25 cases, 16 (64\%) cases showed translocations involving at least one of the $I G$ s $(I G H$, $I G K$ and $I G L$ ) (Fig. 2). Among these 16 cases, 12 had $I G H$ translocation alone, 1 had $I G K$ translocation alone (case 24), and there was 1 case each with a combination of IGH/IGK/IGL (case 3), IGH/IGL (case 10) or IGK/IGL translocation (case 6). Among 9 cases without $I G$ s translocations, 3 cases were associated with $M Y C$ translocation, but none of 9 tumors had BCL2 or BCL6 translocation (Fig. 2). Extra copies of $M A L T 1$ and/or BCL2, suggesting trisomy 18 , were detected in $1(4 \%)$ cases and extra copies of BCL6, suggesting trisomy 3, were detected in 3 (12\%) cases (Supplemental Table S2). Extra copies of MYC or IGs were not detected in any case. In total, 21 (84\%) cases showed some structural or numerical aberrations.

\subsection{Clinicopathological and prognostic comparison}

The correlation between molecular factors and OS or PFS is shown in Fig. 3 and 4, respectively.

\subsubsection{DLBCL, NOS, versus HGBL-DH}

Both cases (2/2) of HGBL-DH showed higher clinical stage and higher MIB-1 index ( $\geq 90 \%)$ (Table 3 and 4).
HGBL-DH exhibited a tendency toward higher frequency of relapse $(2 / 2,100 \%$ versus $7 / 23,30 \%$ ) (Table 3 ) and shorter progression free survival time $(P=.0696)$ as compared with DLBCL, NOS; however, these differences did not reach the level of statistical significance (Fig. 4A).

\subsubsection{DE versus non-DE}

All 4 cases of DE showed higher clinical stage and higher MIB-1 index ( $\geq 90 \%$ ) (Table 4$)$. Three of $4(75 \%)$ cases of DE relapsed, whereas 6 of $21(29 \%)$ cases of non-DEs relapsed $(P=.1162)$; however, these 2 groups did not show significant differences in OS $(P=.6304)$ and PFS $(P=$ .3188) (Fig. 3B and 4B).

\subsubsection{GCB versus non-GCB subtype}

Between GCB $(n=10,25 \%)$ and non-GCB $(n=15$, $75 \%$ ) cases, there were no significant differences in clinicopathological factors (data not shown) or prognosis (Fig. 3C and 4C).

\subsubsection{IGH translocation versus non IGH translocation}

$I G H$ translocation-positive groups showed significantly longer time of OS and PFS as compared with the negative group, respectively ( $P=.0053, .0259)$ (Fig. 3D and 4D). 

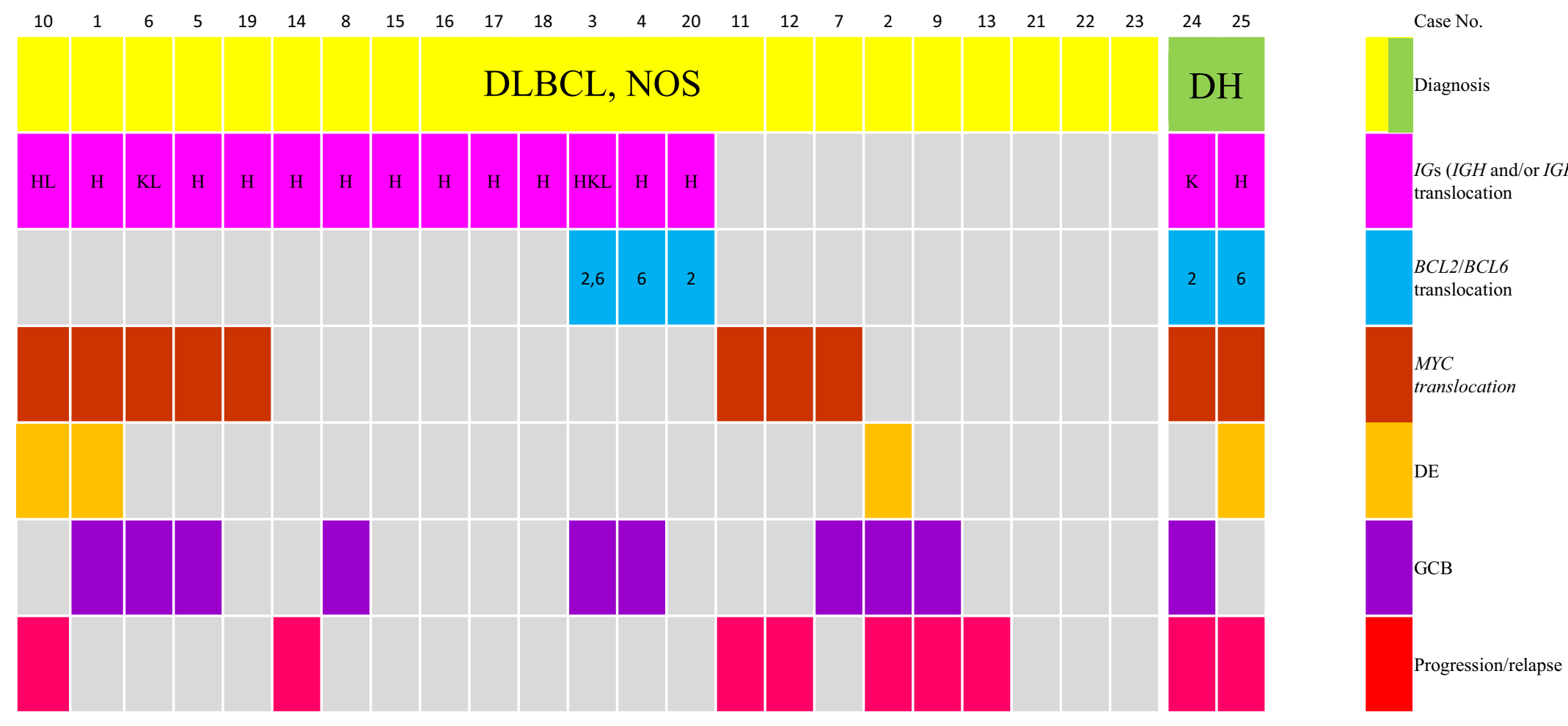

Fig. 2 Histological subtype, $I G$ s rearrangement and other molecular factors in colorectal large B-cell lymphomas. H: $I G H$ translocation; K: $I G L$ translocation; L: IGL translocation; 2: BCL2 translocation; 6: BCL6 translocation 

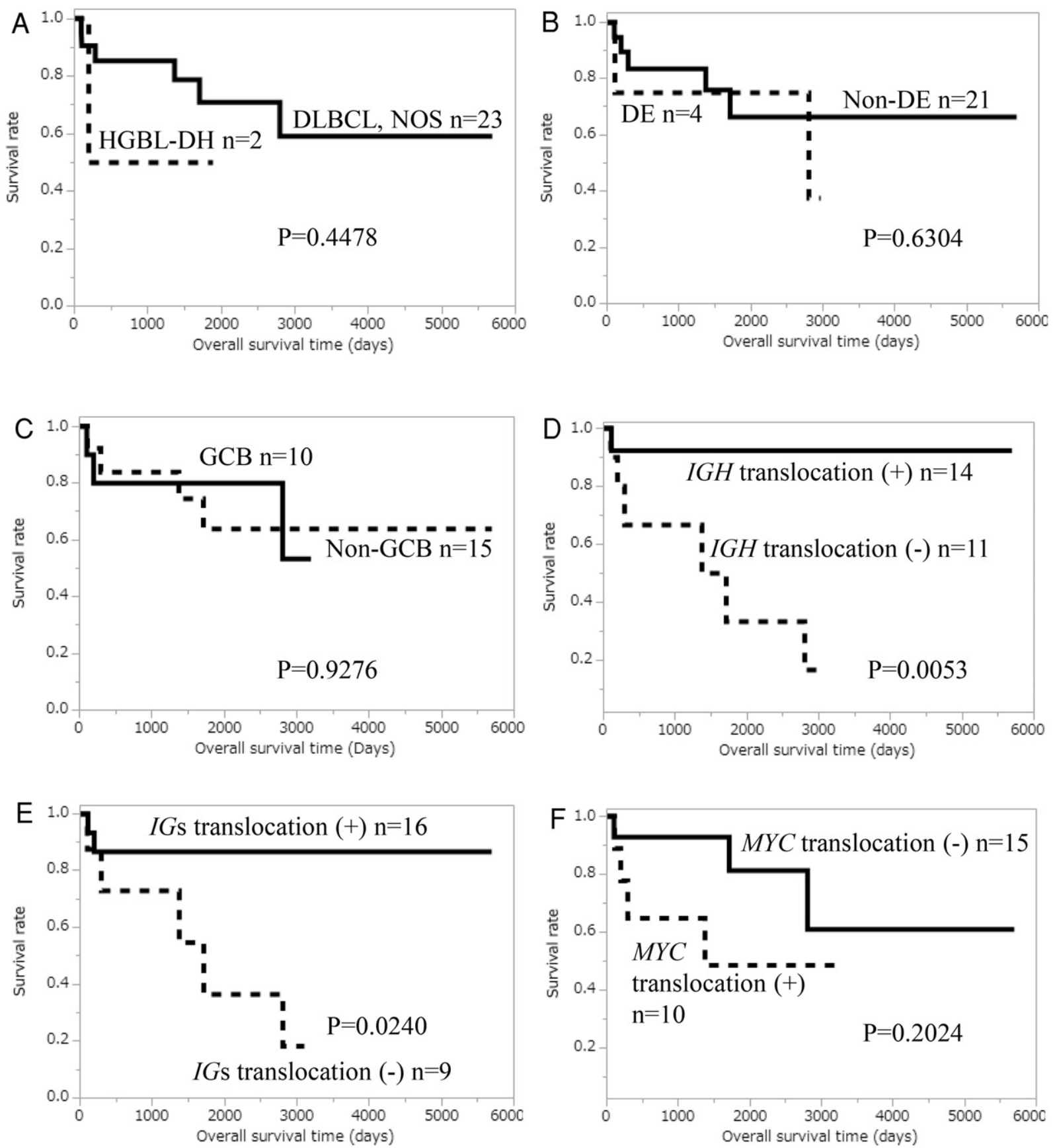

Fig. 3 Kaplan-Meier analysis for overall survival (OS) in colorectal DLBCLs. A, HGBL-DH show slightly worse OS, but without statistical significance $(P=.4478)$. B, There is no significant difference in OS between DEs and non-DEs $(P=.6304)$. C, There is no significant difference in OS between GCB and non-GCB subtypes $(\mathrm{P}=.9276)$. D, Cases involving $I G H$ translocation are correlated with significantly better OS $(P=$ $.0053)$. E, Cases involving $I G$ s translocation are correlated with significantly better OS $(P=.0240)$. F, Cases involving $M Y C$ translocation are associated with slightly worse OS, but not to a statistically significant degree $(P=.2024)$.

\subsubsection{IGs translocation versus non IGs translocation}

The $I G$ s translocation-positive group had longer time of OS $(P=.0240)$ and PFS $(P=.0771)$ as compared with the negative group, although the latter did not reach the level of statistical significance (Fig. 3E and 4E).

\subsubsection{MYC translocation versus non MYC translocation}

The MYC translocation-positive group tended to have worse prognosis compared with the negative group in terms of both OS $(P=.1642)$ and PFS $(P=.2024)$ (Figure $3 F$ and $4 \mathrm{~F})$. In addition, clinical stage $(P=0.0484)$ and MIB-1 index 

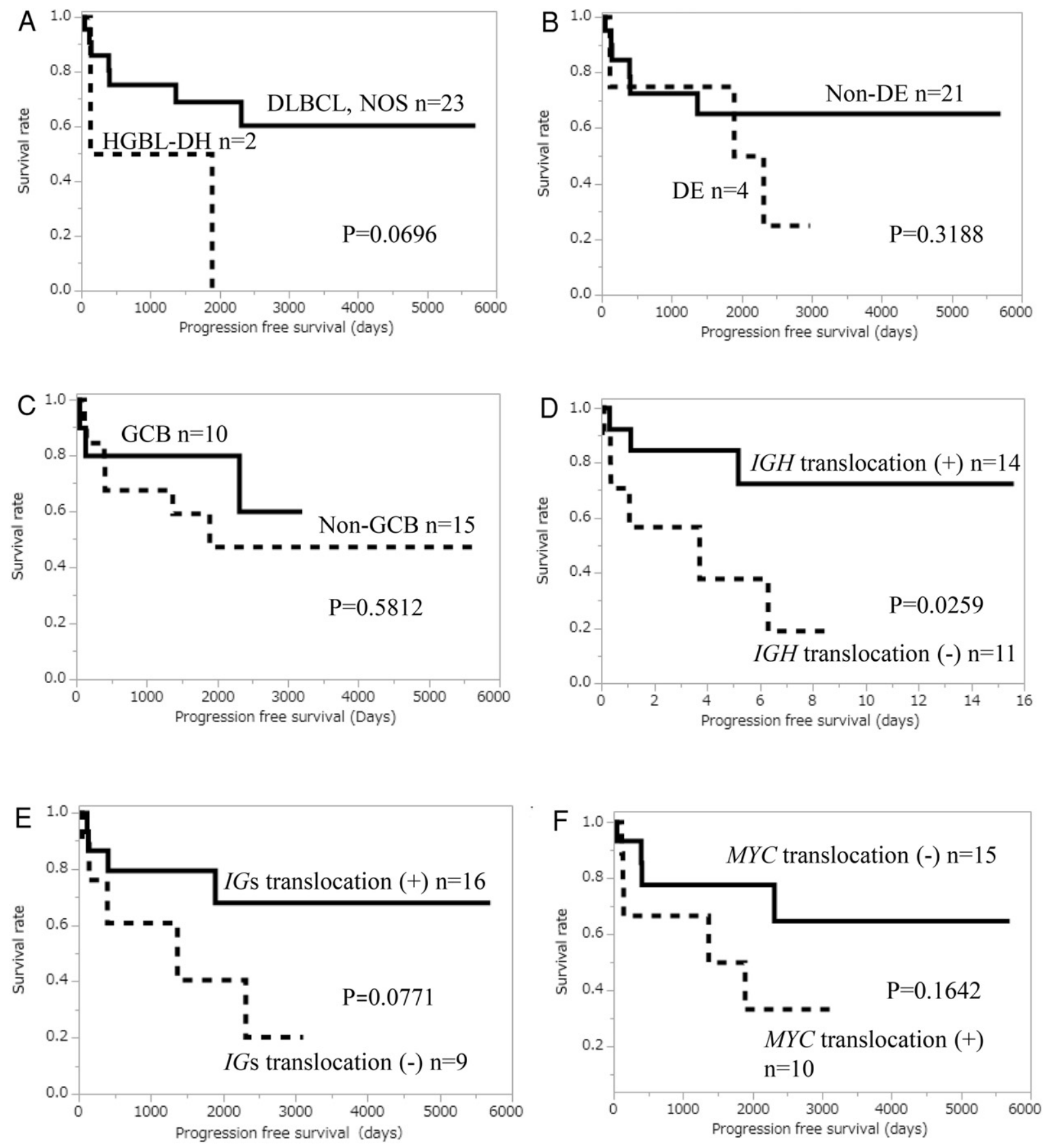

Fig. 4 Kaplan-Meier analysis for progression free survival (PFS) in colorectal DLBCLs. A, HGBL-DH show slightly worse PFS, but the difference does not reach statistical significance $(P=.0696)$. B, DEs show slightly worse PFS, but the difference is not significant $(P=$ .5812). C, Non-GCB subtypes show slightly worse PFS, but statistical difference is not detected $(P=.5812)$. D, Cases involving $I G H$ translocation are correlated with significantly better PFS $(P=.0259)$. E, Cases involving $I G$ s translocation show better PFS, but the difference is not significant $(P=.0771)$. F, Cases involving $M Y C$ translocation are associated with slightly worse prognosis, but the difference is not significant $(P=.1642)$.

$(P=.0325)$ were significantly higher in the $M Y C$ translocation positive group (Table 4).

\subsubsection{Prognostic factors in colorectal DLBCL, NOS}

When the cases were limited to DLBCL, NOS $(\mathrm{n}=$ 23 ), both the presence of $I G H$ translocation and the presence of $I G$ s translocation were correlated with better OS $(P=.0136, P=.0101$, respectively) (Supplemental Fig. S3C, S3E) and PFS $(P=.0304, P=$ .0210 , respectively) (Supplemental Fig. S3D, S3F). Other molecular factors did not influence the prognosis. 


\section{Discussion}

In our study, we detected 2 cases of HGBL-DHs (8\%) among the colorectal DLBCLs; a similar ratio of HGBL-DHs (DHL) has been reported among nodal DLBCLs $[3,11,12]$. Although the number of examined cases was very small in our previous studies on GI-DLBCL, the ratio of DHL was $0 \%$ in the stomach $(n=83)$ and $6 \%$ in the small intestine $(n=33)[20,21]$. Additionally, in a study by Magnoli et al [26], no DHL cases were recognized in any GI organ, including the stomach $(n=5)$, small intestine $(n=5)$, and large intestine $(n=4)$. It has been reported that DHL represents a more aggressive group among nodal DLBCLs [11,12]. In this study, both cases $(2 / 2)$ of DHL showed relapse; 1 case of DHL (case 25) died of tumor, while the other (case 24) experienced a relapse but remained alive for 85 months. It is unclear why the latter case showed a relatively indolent clinical course. These cases had both $I G K$ and $B C L 2$ translocation and GCB phenotype, and thus it might be that the DHL originated from follicular lymphoma [3], although it was difficult to determine the exact origin and clinicopathological significance of such a genotype of DHL. Recently, Miyaoka et al reported that follicular lymphomas with $M Y C$ translocation ("double-hit follicular lymphoma") may have a relatively indolent clinical course [28]. Conversely, among our cases of DLBCL, NOS $(n=23)$, 3 patients (case 3, 4, and 20) had both IGH and BCL2 or BCL6 rearrangements by break-apart FISH (case 20 also had IGH$B C L 2$ translocation by dual-fusion FISH) without MYC translocations and they remained alive without relapse. Morphologically, these 3 cases did not show the definitive findings of follicular lymphoma, but genetically at least some of them might be identical to DLBCL derived from follicular lymphoma and may be consistent with a relatively indolent clinical course.

In this study, $4(16 \%)$ cases of colorectal DLBCL were DE, and $2(8 \%)$ cases were DHL (Table 2 and Supplemental Table S2). In previous studies, among DLBCLs of various sites, about $19 \%$ to $34 \%$ have been reported as DE $[3,26,29]$. However, there have been no studies focusing on the digestive tract. Patients with DE were first noted as a poor prognostic group after R-CHOP, and many cases of DE were later found to belong to activated $B$ cell-like (ABC) subtype $[13,14,29]$. In our series, patients with the DE phenotype showed significantly higher MIB-1 index $(P=.0261)$ (Table 4). In addition, 3 of 4 patients with DE relapsed and two died of lymphoma, but there was no statistically significant difference in prognosis between the $\mathrm{DE}$ and non-DE groups (Fig. 3B and 4B). Thus, the prognostic significance of DE subtypes in GI DLBCL remains to be further elucidated in studies enrolling a larger number of cases.

According to earlier reports on nodal DLBCL, the GCB type accounts for about $35 \%$ to $56 \%$ of cases and has a more favorable prognosis than the non-GCB type [25,30-32]. As for colorectal DLBCL, there are few reports on GCB/non-GCB phenotype, due to its scarcity of colorectal DLBCL itself. As for DLBCL of the stomach and small intestine, the actual ratio of the GCB to non-GCB subtype is controversial, but all reports agree that there is no statistically significant difference in prognosis between
Table 3 Clinicopathological features in DLBCL, NOS, and HGBL-DH

\begin{tabular}{|c|c|c|}
\hline & $\begin{array}{l}\text { DLBCL, NOS } \\
(\mathrm{n}=23,92 \%)\end{array}$ & $\begin{array}{l}\text { HGBL-DH } \\
(\mathrm{n}=2,8 \%) \\
\end{array}$ \\
\hline Male/female & $13: 10$ & $1: 1$ \\
\hline Age median (range) & $65(38-84)$ & $73(68-77)$ \\
\hline \multicolumn{3}{|l|}{ Location } \\
\hline Cecum $(n=17)$ & $16(70)$ & $1(50)$ \\
\hline Colon $(n=4)$ & $3(13)$ & $1(50)$ \\
\hline Rectum $(n=4)$ & $4(17)$ & $0(0)$ \\
\hline \multicolumn{3}{|l|}{ Tumor size } \\
\hline$<10 \mathrm{~cm}(\mathrm{n}=18)$ & $17(74)$ & $1(50)$ \\
\hline$\geq 10 \mathrm{~cm}(\mathrm{n}=7)$ & $6(26)$ & $1(50)$ \\
\hline \multicolumn{3}{|l|}{ Macroscopic type } \\
\hline Ulcerative $(n=11)$ & $10(44)$ & $1(50)$ \\
\hline Polypoid type $(\mathrm{n}=12)$ & $12(52)$ & $0(0)$ \\
\hline Mixed/others $(n=2)$ & $1(4)$ & $1(50)$ \\
\hline \multicolumn{3}{|l|}{ Clinical stage } \\
\hline \multicolumn{3}{|l|}{ (Lugano classification) } \\
\hline $\mathrm{I}, \mathrm{II} 1(\mathrm{n}=11)$ & $11(48)$ & $0(0)$ \\
\hline II2, IIE, IV ( $\mathrm{n}=14)$ & $12(52)$ & $2(100)$ \\
\hline \multicolumn{3}{|l|}{ IPI } \\
\hline Low $(\mathrm{n}=11)$ & $11(48)$ & $0(0)$ \\
\hline Low-intermediate $(\mathrm{n}=7)$ & $5(22)$ & $2(100)$ \\
\hline Intermediate-high $(n=5)$ & $5(22)$ & $0(0)$ \\
\hline High $(n=2)$ & $2(87)$ & $0(0)$ \\
\hline \multicolumn{3}{|l|}{ Colectomy } \\
\hline Yes $(n=18)$ & $17(74)$ & $1(50)$ \\
\hline No $(n=7)$ & $6(26)$ & $1(50)$ \\
\hline \multicolumn{3}{|l|}{ Response $^{\mathrm{a}}$} \\
\hline $\mathrm{CR}(\mathrm{n}=17)$ & $16(70)$ & $1(50)$ \\
\hline$P R(n=4)$ & $3(13)$ & $1(50)$ \\
\hline $\mathrm{NC} / \mathrm{PD}(\mathrm{n}=3)$ & $3(13)$ & $0(0)$ \\
\hline \multicolumn{3}{|l|}{ Progression/relapse } \\
\hline Yes $(n=9)$ & $7(30)$ & $2(100)$ \\
\hline No $(n=16)$ & $16(70)$ & $0(0)$ \\
\hline \multicolumn{3}{|l|}{ Tumor specific death } \\
\hline Yes $(n=7)$ & $6(26)$ & $1(50)$ \\
\hline No $(n=18)$ & $17(74)$ & $1(50)$ \\
\hline
\end{tabular}

Abbreviations: IPI, International Prognostic Index; CR, complete response; PR, partial remission; NC, no change; PD, progressive disease.

${ }^{a}$ One case did not receive an imaging test after initial examination, but did not relapse clinically.

the two subtypes [20,21,33,34]. In our series of colorectal cases, the GCB type accounted for $40 \%$ (10/25) of DLBCLs; moreover, half of the DHL cases (1/2) and half of the DE cases (2/4) were the GCB subtype. As for prognosis, there was no significant prognostic difference between the GCB and non-GCB group. Although the examined number of cases examined in this study was limited, the prevalence and clinicopathological significance of the GCB subtype might be different between GI and nodal DLBCLs. On the other hand, in GI DLBCL, the prognostic value of the GCB/non-GCB phenotype based on a system other than Hans' criteria is still unknown $[31,32]$.

In the present study, IGH translocation was confirmed in 14 cases $(56 \%)$, which was the similar to the frequency in nodal DLBCL [35]. The frequency of IGH translocation in other GI 
Table 4 The correlation between subclassifications and clinical stage or MIB-1 index in colorectal DLBCL

\begin{tabular}{|c|c|c|c|c|c|c|}
\hline & \multicolumn{2}{|c|}{$\begin{array}{l}\text { Clinical stage } \\
\text { (Lugano classification) }\end{array}$} & \multirow[t]{2}{*}{$P$} & \multicolumn{2}{|c|}{ MIB-1 index } & \multirow[t]{2}{*}{$P$} \\
\hline & I/II1 & II2/IIE/IV & & $<90 \%$ & $\geq 90 \%$ & \\
\hline \multicolumn{7}{|l|}{ WHO classification } \\
\hline DLBCL, NOS $(n=23)$ & $11(48)$ & $12(52)$ & \multirow[t]{2}{*}{.3033} & $14(62)$ & $9(38)$ & \multirow[t]{2}{*}{.1833} \\
\hline HGBL-DH $(\mathrm{n}=2)^{\mathrm{a}}$ & $0(0)$ & $2(100)$ & & $0(0)$ & $2(100)$ & \\
\hline \multicolumn{7}{|l|}{ Double expressor (DE) } \\
\hline $\mathrm{DE}(\mathrm{n}=4)$ & $0(0)$ & $4(100)$ & \multirow[t]{2}{*}{.0791} & $0(0)$ & $4(100)$ & \multirow[t]{2}{*}{$.0261 *$} \\
\hline Non-DE $(\mathrm{n}=21)$ & $11(52)$ & $10(48)$ & & $14(67)$ & $7(33)$ & \\
\hline \multicolumn{7}{|l|}{ Hans classification } \\
\hline GCB $(n=10)$ & $2(20)$ & $8(80)$ & \multirow{2}{*}{$.0484 *$} & $4(40)$ & $6(60)$ & \multirow{2}{*}{.1882} \\
\hline Non-GCB $(\mathrm{n}=15)$ & $9(60)$ & $6(40)$ & & $10(67)$ & $5(33)$ & \\
\hline \multicolumn{7}{|l|}{$I G H$ translocation } \\
\hline Positive $(n=14)$ & $5(36)$ & $9(64)$ & \multirow{2}{*}{.2964} & $10(71)$ & $4(36)$ & \multirow{2}{*}{.1160} \\
\hline Negative (n = 11) & $6(55)$ & $5(45)$ & & $4(29)$ & $7(64)$ & \\
\hline \multicolumn{7}{|l|}{$I G$ s translocation } \\
\hline Positive $(\mathrm{n}=16)$ & $5(31)$ & $11(69)$ & \multirow{2}{*}{.1153} & $10(63)$ & $6(37)$ & \multirow{2}{*}{.3827} \\
\hline Negative $(n=9)$ & $6(67)$ & $3(33)$ & & $4(44)$ & $5(56)$ & \\
\hline \multicolumn{7}{|l|}{$M Y C$ translocation } \\
\hline Positive $(\mathrm{n}=10)$ & $2(20)$ & $8(80)$ & \multirow{2}{*}{$.0484 *$} & $3(30)$ & $7(70)$ & \multirow{2}{*}{$.0325 *$} \\
\hline Negative $(\mathrm{n}=15)$ & $9(60)$ & $6(40)$ & & $11(73)$ & $4(27)$ & \\
\hline
\end{tabular}

organs was reported to be $27 \%$ to $70 \%$ in the small intestine and $36 \%$ in the stomach (except for DLBCL with MALToma) [20,21]. As for prognosis, in our series of colorectal DLBCLs, translocations involving $I G H$ were found to be associated with favorable OS and PFS (Fig. 3D and 4D). Even when considering only cases of DLBCL, NOS, the same relationship was confirmed (Supplemental Fig. S3C, S3D). A similar prognostic value of $I G H$ translocation has been reported in DLBCLs of the stomach and small intestine [20,21], whereas it has not been confirmed in nodal DLBCL. It is well known that overexpression of IGH partner genes such as BCL2, BCL6 and MYC plays an important role in lymphomagenesis; presumably, however, additional alterations are also indispensable for the development and progression of DLBCL [18]. The differences in the gene alterations involved might influence the above-mentioned prognostic impact of $I G H$-translocation in GI-DLBCL. In addition, it is possible that the genes responsible for the development of lymphoma are different between the GI tract and nodal DLBCLs.

Meanwhile, translocation of $I G$ s (IGH and/or $I G K$ and/or $I G L)$ was found in 16 cases $(64 \%)$ of colorectal DLBCL. Among the 16 cases, 1 case without $I G H$ translocation had $I G K$ translocation (case 24) and 1 case without $I G H$ translocation had both $I G K$ and $I G L$ translocations (case 6). In one patient with $I G H$ translocation, we also found concomitant translocations involving both $I G K$ and $I G L$; this is a rare phenomenon that has only been reported in nodal DLBCL [19,36]. Interestingly, similar to $I G H$ translocation, the presence of $I G$ s translocation was associated with favorable prognosis in our patients with colorectal DLBCL $(n=25)$ (Fig. 3E and 4E) or in those with DLBCL, NOS ( $n=23$ ) (Supplemental Fig. S3E, S3F). As for gastric and small intestinal DLBCL, to the best of our knowledge, there have been no investigations on the prognostic relevance of $I G$ s translocation. Akasaka et al [37] reported that $B C L 6-I G$ gene fusions were associated with a better prognosis than $B C L 6$-non- $I G$ fusions in patients with nodal DLBCL.

We still cannot fully explain the reason for the favorable prognosis of patients with $I G$ s translocation. Nevertheless, the examination of $I G$ s translocation might be helpful for the prognostic prediction of colorectal DLBCL. Further studies will be needed to confirm whether these translocations truly influence the prognosis of gastrointestinal DLBCL and to elucidate the underlying molecular mechanism.

In conclusion, we comprehensively examined the immunophenotype and candidate gene rearrangements in cases of colorectal DLBCL and revealed that $8 \%$ of these patients had the "so-called double-hit". We also found that translocation involving at least one of $I G H, I G K$, and $I G L$ was associated with more favorable behavior in our patients with DLBCL or DLBCL, NOS. Therefore, identifying the translocations of $I G$ s as well as MYC and BCL2/BCL6 may be useful for the diagnosis and prognostic prediction of colorectal DLBCL.

\section{Appendix A. Supplementary data}

Supplementary data to this article can be found online at https://doi.org/10.1016/j.humpath.2019.09.003. 


\section{References}

[1] Müller-Hermelink HK, Delabie J, Ko YH, et al. B-cell lymphoma of the colon and rectum. In: Bosman FT, Carneiro F, Hruban RH, et al, eds. WHO Classification of Tumours of the Digestive System, Fourth edition. Lyon: IARC Press; 2010:178-180.

[2] Nakamura S, Matsumoto T, lida M, Yao T, Tsuneyoshi M. Primary gastrointestinal lymphoma in Japan: a clinicopathologic analysis of 455 patients with special reference to its time trends. Cancer 2003;97:2462-73.

[3] Gascoyne RD, Campo E, Jaffe ES, et al. Diffuse large B-cell lymphoma, not otherwise specified. In: Swerdlow SH, Campo E, Harris NL, et al, editors. World Health Organization classification of tumours of haematopoietic and lymphoid tissues. Revised 4th edition. Lyon: IARC Press; 2017.

[4] Cai YB, Chen HY, He JJ, et al. The role of surgical intervention in primary colorectal lymphoma: A SEER population-based analysis. Oncotarget 2016;44:72263-75.

[5] Lai YL, Lin JK, Liang WY, Huang YC, Chang SC. Surgical resection combined with chemotherapy can help achieve better outcomes in patients with primary colonic lymphoma. J Surg Oncol 2011;104:265-8.

[6] Nakamura S, Matsumoto T, Iida M, et al. Endoscopic diagnosis of intestinal malignant lymphoma diagnosis and management of gastrointestinal lymphomas. Gastroenterol Endosc 2009;51:3-9.

[7] Howell JM, Auer-Grzesiak I, Zhang J, Andrews CN, Stewart D, Urbanski SJ. Increasing incidence rates, distribution and histological characteristics of primary gastrointestinal non-Hodgkin lymphoma in a North American population. Can J Gastroenterol 2012;26:452-6.

[8] Schmitz R, Wright GW, Huang DW, et al. Genetics and pathogenesis of diffuse large B-cell lymphoma. N Engl J Med 2018;378:1396-407.

[9] Pasqualucci L, Dalla-Favera R. Genetics of diffuse large B-cell lymphoma. Blood 2018;131:2307-19.

[10] Lohr JG, Stojanov P, Lawrence MS, et al. Discovery and prioritization of somatic mutations in diffuse large B-cell lymphoma (DLBCL) by wholeexome sequencing. Proc Natl Acad Sci USA 2012;109:3879-84.

[11] Aukema SM, Siebert R, Schuuring E, et al. Double-hit B-cell lymphomas. Blood 2011;117:2319-31.

[12] Johnson NA, Savage KJ, Ludkovski O, et al. Lymphomas with concurrent $B C L 2$ and $M Y C$ translocations: the critical factors associated with survival. Blood 2009;114:2273-9.

[13] Molina TJ, Canioni D, Copie-Bergman C, et al. Young patients with nongerminal center B-cell-like diffuse large B-cell lymphoma benefit from intensified chemotherapy with ACVBP plus rituximab compared with CHOP plus rituximab: analysis of data from the Groupe d'Etudes des Lymphomes de l'Adulte/lymphoma study association phase III trial LNH 03-2B. J Clin Oncol 2014;32:3996-4003.

[14] Green TM, Young KH, Visco C, et al. Immunohistochemical double-hit score is a strong predictor of outcome in patients with diffuse large B-cell lymphoma treated with rituximab plus cyclophosphamide, doxorubicin, vincristine, and prednisone. J Clin Oncol 2012;30:3460-7.

[15] Kawamoto K, Miyoshi H, Yoshida N, et al. MYC translocation and/or BCL2 protein expression are associated with poor prognosis in diffuse large B-cell lymphoma. Cancer Sci 2016;107:853-61.

[16] Alizadeh AA, Eisen MB, Davis RE, et al. Distinct types of diffuse large B-cell lymphoma identified by gene expression profiling. Nature 2000;403:503-11.

[17] Papakonstantinou IP, Andreadis EA. Persistent afebrile abdominal pain: an usual case of segmental colitis in an immunocompromised host. Cureous 2017;9:e1033.

[18] Kramer MH, Hermans J, Wijburg E, et al. Clinical relevance of BCL2, BCL6 and MYC rearrangements in diffuse large B-cell lymphoma. Blood 1998;92: 3152-62.

[19] $\mathrm{Lu} \mathrm{C}, \mathrm{He} \mathrm{Q}, \mathrm{Zhu} \mathrm{W}$, et al. The value of detecting immunoglobulin gene rearrangements in the diagnosis of B-cell lymphoma. Oncotarget 2017;8: 77009-19.

[20] Ikegami K, Nakamura S, Esaki M, et al. Prognostic value of chromosomal translocations in small-bowel diffuse large B-cell lymphoma. Histopathology 2016;68:199-209.
[21] Nakamura S, Ye H, Bacon CM, et al. Translocations involving the immunoglobulin heavy chain gene locus predict better survival in gastric diffuse large B-cell lymphoma. Clin Cancer Res 2008;14: 3002-10.

[22] Lewin KJ, Ranchod M, Dorfman RF. Lymphomas of the gastrointestinal tract: a study of 117 cases presenting with gastrointestinal disease. Cancer 1978;42:693-707.

[23] Rohatiner A, d'Amore F, Coiffier B, et al. Report on a workshop convened to discuss the pathological and staging classifications of gastrointestinal tract lymphoma. Ann Oncol 1994;5:397-400.

[24] The International Non-Hodgkin's Lymphoma Prognostic Factors Project. A predictive model for aggressive non-Hodgkin's lymphoma. N Engl J Med 1993;329:987-94.

[25] Hans CP, Weisenburger DD, Greiner TC, et al. Confirmation of the molecular classification of diffuse large B-cell lymphoma by immunohistochemistry using a tissue microarray. Blood 2004;103:275-82.

[26] Magnoli F, Bernasconi B, Vivian L, et al. Primary extranodal diffuse large B-cell lymphomas: Many sites, many entities? Clinico-pathological, immunohistochemical and cytogenetic study of 106 cases. Cancer genet 2018;228-229:28-40.

[27] Yamamoto H, Kohashi K, Oda Y, et al. Absence of human herpesvirus- 8 and Epstein-Barr virus in inflammatory myofibroblastic tumor with anaplastic large cell lymphoma kinase fusion gene. Pathol Int 2006;56:584-90.

[28] Miyaoka M, Kikuti YY, Carreas J, et al. Clinicopathological and generic analysis of double-hit follicular lymphoma: comparison with high-grade B-cell lymphoma with BCL2 and/or BCL6 rearrangements. Mod pathol 2018;31:313-26.

[29] Johnson NA, Slack GW, Savage KJ, et al. Concurrent expression of $M Y C$ and BCL2 in diffuse large B-cell lymphoma treated with rituximab plus cyclophosphamide, doxorubicin, vincristine. and prednisone J Clin Oncol 2012;30:3452-9.

[30] Rosenwald A, Wright G, Chan WC, et al. The use of molecular profiling to predict survival after chemotherapy for diffuse large-B-cell lymphoma. N Engl J Med 2003;346:1937-47.

[31] Choi WW, Weisenburger DD, Greiner TC, et al. A new immunostain algorithm classifies diffuse large B-cell lymphoma into molecular subtypes with high accuracy. Clin Cancer Res 2009;15: 5494-502.

[32] Visco C, Li Y, Xu-Monette ZY, et al. Comprehensive gene expression profiling and immunohistochemical studies support application of immunophenotypic algorithm for molecular subtype classification in diffuse large B-cell lymphoma: A report from the International DLBCL Rituximab-CHOP Consortium Program Study. Leukemia 2012:26:2103-13.

[33] Ishikawa E, Kato S, Shimada K, et al. Clinicopathological analysis of primary intestinal diffuse large B-cell lymphoma: Prognostic evaluation of CD5, PD-L1, and Epstein-Barr virus on tumor cells. Cancer Med 2018(12):6051-63.

[34] Ishikawa E, Kato S, Shimada K, et al. A prognostic model, including the EBV status of tumor cells, for primary gastric diffuse large B-cell lymphoma in the rituximab era. Cancer Med 2018;7:3510-20.

[35] Bernicot I, Douet-Guilbert N, Le Bris MJ, Herry A, Morel F, Braekeleer De. Molecular cytogenetics of $I G H$ rearrangements in non-Hodgkin B-cell lymphoma. Cytogenet Genome Res 2007;118:345-52.

[36] Akasaka H, Akasaka T, Kurata M, et al. Molecular anatomy of BCL6 translocation revealed by long-distance polymerase chain reaction cased assays. Cancer Res 2000;60:2335-41.

[37] Akasaka T, Ueda C, Kurata M, et al. Non immunoglobulin (non $I g$ )/BCL6 gene fusion in diffuse large B-cell lymphoma results in worse prognosis than Ig/BCL6. Blood 2000;96:2907-9. 